To be published in the proceedings of the International Symposium on

Superconductiivty (ISS'96), October 21-24, Sapporo Hokkaido, Japan.

$$
\text { CONF-961076--3 }
$$

\title{
FABRICATION OF HIGH CRITICAL CURRENT DENSITY SUPERCONDUCTING TAPES BY EPITAXIAL DEPOSITION OF YBCO THICK FILMS ON BIAXIALLY TEXTURED METAL SUBSTRATES
}

\author{
A. GOYAL, D. P. NORTON, M. PARANTHAMAN, J. D. BUDAI. E. D. SPECHT, \\ D.K.CHRISTEN, D. M. KROEGER, Q. HE , B. SAFFIAN, F. A. LIST. D. F. LEE, C. E. \\ KLABUNDE AND P. M. MARTIN
}

Oak Ridge National Laboratory, PO Box 2008, Oak Ridge, TN 37831-6116.

\section{ABSTRACT}

High critical current density $\mathrm{YBa}_{2} \mathrm{Cu}_{3} \mathrm{O}_{7 . \delta}(\mathrm{YBCO})$ tapes were fabricated by epitaxial deposition on rolling-assisted-biaxially-textured-substrates (RABiTS). The RABiTS technique uses well established, industrially scaleable, thermomechanical processes to impart a strong biaxial texture to a base metal. This is followed by vapor deposition of epitaxial buffer layers to yield chemically and structurally compatible surfaces. Epitaxial YBCO films grown on such substrates have critical current densities approaching $10^{6} \mathrm{~A} / \mathrm{cm}^{2}$ at $77 \mathrm{~K}$ in zero-field and have field dependences similar to epitaxial films on single crystal ceramic substrates. Deposited conductors made using this technique offer a potential route for the fabrication of long lengths of high $\mathrm{J}_{\mathrm{c}}$ wire capable of carrying high currents in high magnetic fields and at elevated temperatures.

\section{INTRODUCTION}



Practical applications of high- $T_{c}$ superconductors require the fabrication of these materials into tapes or wires with high critical current density $\left(J_{c}\right)$. Progress towards this goal has been hindered predominantly by the strong dependence of critical current density, $J_{c}$, on grain boundary misorientation angle [1]. Most high angle boundaries act as weak-links or barriers to current flow. Since bulk superconductors contain many grains resulting in numerous grain boundaries. macroscopic biaxial alignment of grains to skew the grain boundary misorientation distribution to low angle boundaries is desired for high $\mathrm{J}_{:}^{\prime}$ 's. This has recently been demonstrated by epitaxial deposition of YBCO thick films on biaxially textured substrates made using the ion-beam-assisted-deposition (IBAD) [2]. A related technique called modified bias sputtering was used by Fukotomi et al. [3] to obtain biaxially textured $Y-123$ films. $J_{c}$ values in the range of $10^{5}-10^{6} \mathrm{~A} / \mathrm{cm}^{2}$ have been demonstrated by these techniques. However. in each of these cases. deposition of the biaxially textured buffer layer is slow, since a predominant fraction of the material deposited is removed by the impinging ions which ensure that unfavorable orientations do not survive. Furthermore, scaleup of these processes to long lengths appears to be complicated. Nevertheless, success in obtaining high- $J_{c}$ films by the IBAD process has heightened interest worldwide in finding simple and easily scaleable methods to produce long lengths of biaxially textured substrates. We have recently demonstrated that biaxially textured substrates can be made using simple thermomechanical processes followed by epitaxial deposition of buffer layers [4-7]. YBCO thick films grown epitaxially on these substrates also exhibit $J_{c}$ 's in the range of $10^{5}-10^{6} \mathrm{~A} / \mathrm{cm}^{2}$ [4.5]. This paper summarizes the results obtained so far using the RABiTS technique.

\section{RESULTS AND DISCUSSIONDISTRIBUTION OF THIS DOCURENT IS UNLMITED}

Figure 1 shows a (111) pole figure for a cube textured $\mathrm{Ni}(99.99 \%)$ tape produced by coldrolling to $>90 \%$ deformation followed by recrystallization at $1000^{\circ} \mathrm{C}$ for 4 hrs [4]. The presence of a sharp, well-developed, single component cube texture is evident. Typical samples have $X$-ray $\omega$ - and $\phi$-scans with full-width-half-maximum (FWHM) of $6^{\circ}$ and $7^{\circ}$ respectively. The texture was found to be stable to temperatures as high as $1300^{\circ} \mathrm{C}$. Samples as long as $1 \mathrm{~m}$ have been fabricated and good in-plane texture was observed along the sample length. Examination of grain boundary misorientations in $\mathrm{mm}$ size regions of the substrate, comprising over 100 interconnected grain boundaries indicated that over $95 \%$ of the grain boundaries have misorientation angles less than $10^{\circ}$. Typical grain sizes are in the range of $50-100 \mu \mathrm{m}$. Control 


\section{DISCLAIMER}

Portions of this document may be illegible in electronic image products. Images are produced from the best available original document. 


\section{DISCLAIMER}

This report was prepared as an account of work sponsored by an agency of the United States Government. Neither the United States Government nor any agency thereof, nor any of their employees, makes any warranty, express or implied, or assumes any legal liability or responsibility for the accuracy, completeness, or usefulness of any information, apparatus, product, or process disclosed, or represents that its use would not infringe privately owned rights. Reference herein to any specific commercial product, process, or service by trade name, trademark, manufacturer, or otherwise does not necessarily constitute or imply its endorsement, recommendation, or favoring by the United States Government or any agency thereof. The views and opinions of authors expressed herein do not necessarily state or reflect those of the United States Government or any agency thereof. 

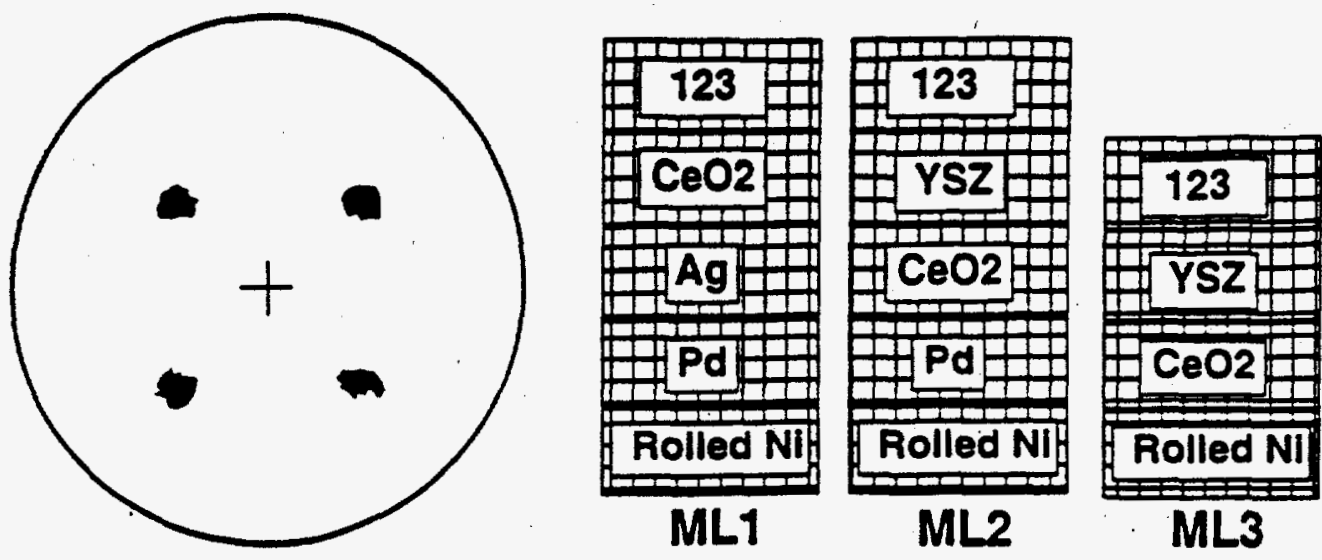

Fig.l (on left): (111) X-ray pole figure for a rolled and recrystallized $\mathrm{Ni}$ sheet. (111) peak positions indicate the presence of only the $\{100\}<001>$ cube orientation.

Fig.2 (on right): Schematic representations of cross-sections of three RABiT multilayer structures.

of roll surfaces leads to as-rolled tapes with rms surface roughness of $50 \mathrm{~nm}$, determined using an atomic force microscope (AFM). Smooth substrate surfaces are essential for growth of high quality films. The choice of $\mathrm{Ni}$ over noble metals stems from the ease in producing a single component. sharp biaxial texture and its significantly lower cost.

In order to grow high quality epitaxial superconducting films on the biaxially textured $\mathrm{Ni}$ substrate. a chemical and structural buffer layer is required. Typically, the desired buffer lavers for YBCO film growth are oxides. Hence the task of fabricating a suitable substrate for epitaxial deposition of the superconductor involves epitaxial deposition of oxide buffer layers on $\mathrm{Ni}$. This is difficult because of the ease of surface oxide formation on $\mathrm{Ni}$ under the typical oxidizing conditions required for oxide film growth. Although the surface oxide on $(100) \mathrm{Ni}$ can be epitaxiai. it typically forms a (111) textured $\mathrm{NiO}$ layer. the orientation of which is unsuitable for good YBCO films since many high angle boundaries are present. We have found two methods so far that have proven successful in producing good epitaxial oxide buffer layer films on rolled and recrystallized $\mathrm{Ni}$. The first involves epitaxial deposition of noble metal layers on $\mathrm{Ni}[4.6 .7]$ followed by deposition of oxides and the second involves deposition of oxides directly on $\mathrm{Ni}$ under reducing conditions [5,6,7]. In this paper, two multi-layer structures fabricated using the first technicue, and one structure fabricated using the second technique are described. Figure 2 shows the three multi-layer structures - ML1, ML2 and ML3. ML1 and ML2 are fabricated using the first technique and ML3 by the second technique.

Figure 3 shows $\Phi$-scans showing the in-plane texture for YBCO films on the ML2 multi-layer $\mathrm{RABiT}$ substrate [4]. In this configuration oxide buffer layers are deposited on $\mathrm{Pd}$ coated $\mathrm{Ni}$. The $X$-ray $\phi$-scans exhibit the characteristic four-fold in-plane symmetry with excellent transference of the texture from the $\mathrm{Ni}\left(\Delta \phi=8^{\circ}\right)$ to the YBCO layer $\left(\Delta \phi=8^{\circ}\right)$. The Pd layer was grown using electron beam evaporation at $500^{\circ} \mathrm{C}$ and the $\mathrm{CeO}_{2}$ and $\mathrm{YSZ}$ layers were grown using laser ablation at temperatures ranging from $100-900^{\circ} \mathrm{C}$. The thickness of the Pd layer was $-200 \mathrm{~nm}$ and the total thickness of the oxide layers was $-1 \mu \mathrm{m}$. Oxide buffer layers on Pd have also been grown using DC sputtering [5] and electron beam evaporation [6]. The YBCO film was grown using laser ablation at $780^{\circ} \mathrm{C}$. Figure 3 does not show a phi-scan for the Pdlayer since the $\mathrm{Pd}$ had diffused into the $\mathrm{Ni}$ during the subsequent deposition of other layers. The $T_{c}$ onset of this film was $91 \mathrm{~K}$ and $T_{c}$ (zero) of $87.7 \mathrm{~K}$. Critical current density of the film was measured on a bridge $0.4 \mathrm{~cm}$ long and $0.26 \mathrm{~cm}$ wide. The thickness of the YBCO film was $-0.75 \mu \mathrm{m}$. The zero-field transport $\mathrm{J}_{\mathrm{c}}$ of the film was $3 \times 10^{5} \mathrm{~A} / \mathrm{cm}^{2}$, at $77 \mathrm{~K}$. The field dependence of $\mathrm{J}_{\mathrm{c}}$ for $\mathrm{H} / / \mathrm{C}$ at $77 \mathrm{~K}$ is shown in Figure 4. Also shown in the figure is data for the ML1 multi-layer configuration. This configuration of the RABiT substrate comprises epitaxial deposition of $\mathrm{Ag}$ followed by $\mathrm{CeO}_{2}$ on the Pd buffered $\mathrm{Ni}$. In this case a lower zerofield $J_{s}$ was obtained. This is ascribed to less perfect epitaxy $\left(\mathrm{Ni}_{\Delta \Delta}=8^{\circ}, \mathrm{YBCO}_{\triangle \Delta}=12^{\circ}\right)$ and 
incomplete coverage of the YBCO film [4]. However, the in-field properties are quite similar to the film on ML2 RABiT substrate. In both the cases, the magnetic field dependence of $J_{c}$ is similar to that measured for epitaxial $\mathrm{YBCO}$ films on single crystal $\mathrm{SrTiO}_{3}$, as shown in Figure 4. Also shown in Figure 4, are $\mathrm{J}_{c}(77 \mathrm{~K})$ for an epitaxial, laser ablated, 7$]-1223$ film on $\mathrm{LaAlO}_{3}$ [8] and $J_{c}(75 \mathrm{~K})$ for a $0.8 \mathrm{Gev}$ proton irradiated $\mathrm{Bi}-2223 / \mathrm{Ag}$ powder-in-tube sample [9]. The proton irradiation in the $\mathrm{Bi}-2223$ sample resulted in columnar defects of effective cross-section area density $\mathrm{B}_{0}=1.1 \mathrm{~T}$. Since the data for $\mathrm{Tl}-1223$ and $\mathrm{Bi}-2223$ is representative of the best materials made so far, the superior properties of YBCO conductors on RABiT substrates is evident.

Figure 4 also shows $J_{c}(H)$ of an epitaxial YBCO film $(1.4 \mu \mathrm{m})$ on a RABiT substrate made using the second technique and comprising $\mathrm{Ni}(125 \mu \mathrm{m}) / \mathrm{CeO}_{2}(500 \mathrm{~nm}) / \mathrm{YSZ}(500 \mathrm{~nm})$. The YBCO film and the oxide buffer layers were grown using laser ablation. (100) epitaxy of $\mathrm{CeO}_{2}$ on $\mathrm{Ni}(100)$ was achieved by introducing $4 \% \mathrm{H}_{2} / \mathrm{Ar}$ into the ablation chamber during the initial stages of film growth to prevent oxidation of the Ni surface [5]. This is followed by deposition of YSZ. Temperatures of deposition range between $100-900^{\circ} \mathrm{C}$ [5]. The YBCO film was laser ablated at a substrate temperature of $780^{\circ} \mathrm{C}$ [5]. The zero-field $\mathrm{J}_{\mathrm{c}}$ of this sample as indicated in Figure 4, was $6.34 \times 10^{5} \mathrm{~A} / \mathrm{cm}^{2}$. Its in-field properties are similar to the films on $\mathrm{MLI}$ and ML2 RABiT substrates. Improved $J_{-}$in this configuration is partly ascribed to better in-plane alignment in the starting $\mathrm{Ni}\left(\mathrm{Ni}_{\Delta \circ}=6.8^{\circ}\right)$ and good epitaxy resulting in same in-plane orientation, $\Delta \phi=6.8^{\circ}$, for the YBCO film. Films with $\mathrm{J}_{\mathrm{c}}{ }^{\mathrm{s}} \mathrm{s}$ as high as $7.3 \times 10^{5} \mathrm{~A} / \mathrm{cm}^{2}$ have been fabricated on RABiT substrates made using this architecture (ML3). These values are comparable to the highest values reported for epitaxial YBCO on textured IBAD substrates [2].

Figure 5 shows the temperature dependence of $J_{\mathrm{c}}$ for the YBCO film on the last multi-layer. ML3. Transpor $J_{c}$ vs temperature is shown for fields of $0,1,3,5$ and 8 Tesla. The $J_{c}-T$ dependence is similar to that obtained for films on IBAD substrates [2] and on epitaxial films on single crystal substrates. Also shown for comparison are iypical $\mathrm{J}_{\epsilon}-\mathrm{T}$ data for a $\mathrm{Bi}-2223 / \mathrm{Ag}$

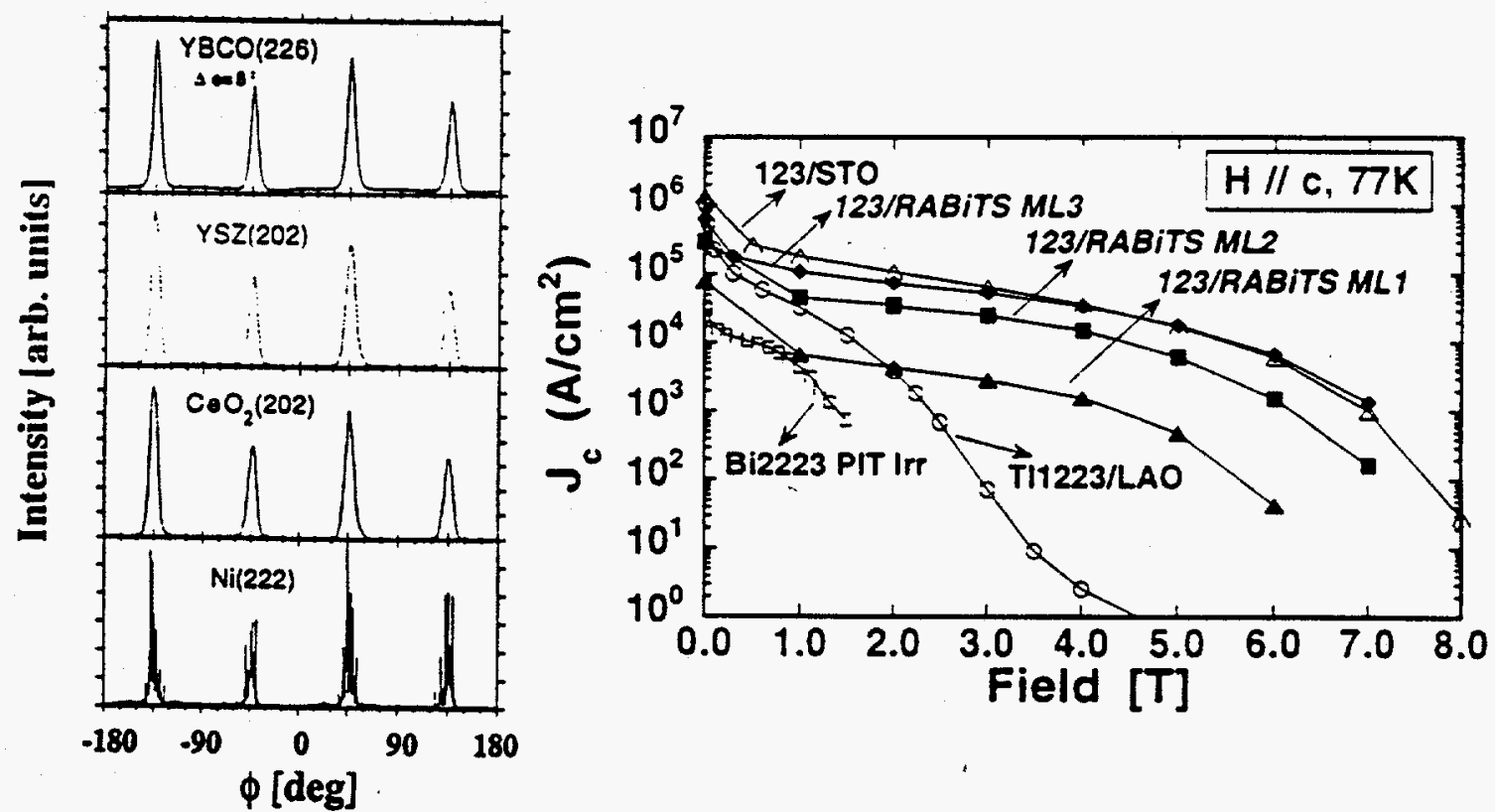

Fig.3 (on left): $X$-ray $\phi$-scans showing the transference of texture for a RABiT substrate comprising $\mathrm{Y}-123([100]+[010])\|\mathrm{YSZ}<110>\| \mathrm{CeO}_{2}<110>\| \mathrm{Pd}<100>/ \mathrm{Ni}<100>$. The $\mathrm{Pd}$ layer is not shown since it had interdiffused with the Ni prior to measurement.

Fig.4: (on right) Field dependence of $J_{c}$ at $77 \mathrm{~K}$ for Hllc for epitaxial $\mathrm{Y}-123$ films on single crystal $\mathrm{SrTiO}_{2}$ and RABiT substrates $\mathrm{ML} 1, \mathrm{ML} 2$ and ML3. Also shown for comparison are data for Tl-1223/ $\mathrm{LaAlO}_{3}[8]$ and $\mathrm{Bi}-2223 / \mathrm{Ag}$ irradiated PIT sample [9]. 


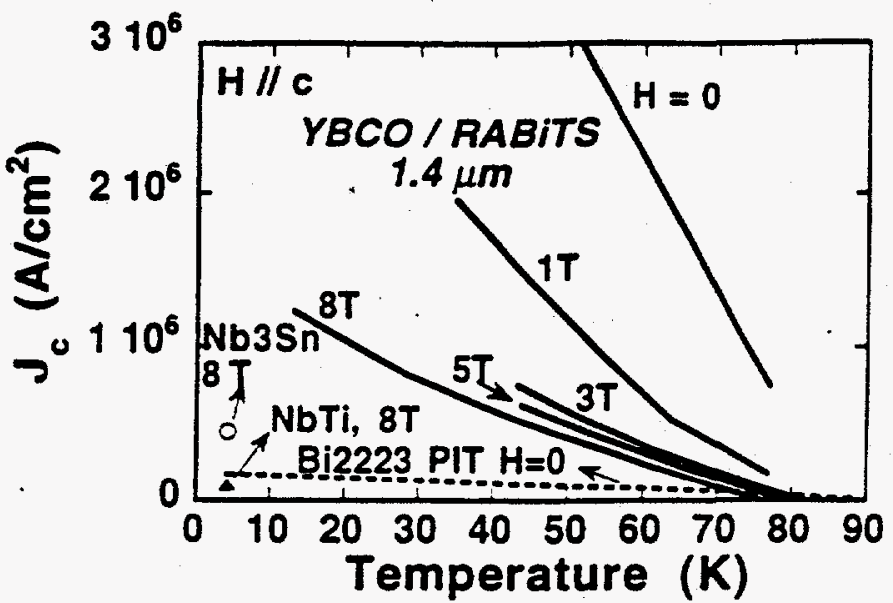

Fig.5:Temperature dependence of $\mathrm{J}_{\mathrm{c}}$ for YBCO film on ML3 RABiT substrate [5]. Also shown for comparison is data for $\mathrm{Bi}-2223$ PIT. [10], $\mathrm{Nb}_{3} \mathrm{Sn}$ and $\mathrm{NbTi}[11]$.

powder-in-tube tape [10], and for $\mathrm{Nb}_{3} \mathrm{Sn} \mathrm{[11]} \mathrm{and} \mathrm{NbTi}[11]$ at $4.2 \mathrm{~K} .8 \mathrm{~T}$. As shown in figure 5, $\mathrm{J}_{c}(8 \mathrm{~T})$ for YBCO films on RABiTS is higher than that for Bi-2223/Ag tapes at zero-field at all temperatures less than $70 \mathrm{~K}$. Moreover. at all temperatures less than $40 \mathrm{~K}, J_{\varepsilon}(8 \mathrm{~T})$ for $\mathrm{YBCO}$ films on $\mathrm{RABiTS}$ is higher than that for $\mathrm{Nb}_{3} \mathrm{Sn}$ and $\mathrm{NbTi}$ at $4.2 \mathrm{~K}$.

In summary, epitaxial deposition of superconductors on substrates made using the RABiTS technique provide a route for the fabrication of long lengths of high- $\mathrm{J}_{\mathrm{c}}$ conductors. A key component of the RABiTS technique is the sharp biaxial texture of a base metal which we have obtained in long lengths. The typical in-plane texture of $7^{\circ}$ that has been achieved in the rolled and annealed $\mathrm{Ni}$ is comparable to the highest reported in IBAD buffer layers (12 ${ }^{\circ}$ [2]. Epitaxial metal and/or ceramic buffer layers are deposited on the base metal to provide a chemically benign and structurally compatible surface for subsequent deposition of the superconductor. High critical currents approaching $10^{6} \mathrm{~A} / \mathrm{cm}^{2}$ were obtained on YBCO films on RABiTS. The in-field properties of the films are similar to those of good quality single crystal films on ceramic substrates. Moreover, the $J_{c}$ of such YBCO conductors is significantly superior to the best $\mathrm{Bi}-2223 / \mathrm{Ag}$ tapes below $70 \mathrm{~K}$ and is comparable at $40 \mathrm{~K}$ to $\mathrm{Nb}_{3} \mathrm{Sn}$ at $4.2 \mathrm{~K}$.

\section{ACKNOWLEDGMENTS}

Research sponsored by U.S. Department of Energy, Office of Efficiency and Renewable Energy. Office of Utility Technology - Superconductivity Program and the Office of Energy Research. Basic Energy. Sciences, managed by Lockheed-Martin Energy Research Corporation for the U.S. Department of Energy under contract DE-AC05-960R22464.

\section{REFERENCES}

1. A. Goyal, et al., J. of Metals, Minerals and Materials, Oct. issue, 1996.

2. Y. Iijima. et al., Appl. Phys. Lett. 60, 769, 1992; R. P. Reade, et al., Appl. Phys. Lett. 61. 2231 (1992); X. D. Wu, et al., Appl. Phys. Lett., 67, 2397 (1995).

3. M. Fukutomi, et al., Physica C 231, 113 (1994).

4. A. Goyal et al., Appl. Phys. Lett., 69, 1795 (1996).

5. D. P. Norton, et al., To be published in Science, 1996.

6. Q. He, et al.. Submitted to Physica C, 1996.

7. M. Paranthaman, et al., Submitted to Physica C, 1996.

8. J. H. Wang et al., Physica C, 245, 171 (1995)..

9. H. Safar et al., Appl. Phys. Lett., 67, 130 (1995).

10. P. Haldar et al., Appl. Phys. Lett., 61, 604 (1992).

11. D. R. Tilley and J. Tilley, Superfluidity and Superconductivity (IOP, Bristol, England, ed. 3. 1990) p. 235. 